\title{
Inflammatory pseudotumor of the epididymis: a case report and review of the literature
}

\author{
Recep Bedir ${ }^{1}$, İbrahim Şehitoğlu ${ }^{1}$, Hakkı Uzun², Cüneyt Yurdakul ${ }^{1}$
}

'Department of Pathology, Faculty of Medicine, Recep Tayyip Erdoğan University, Rize, Turkey

2Department of Urology, Faculty of Medicine, Recep Tayyip Erdoğan University, Rize, Turkey

Submitted:

18.02.2013

Accepted:

20.03.2013

Available Online Date:

16.05.2014

Correspondence:

Recep Bedir

Department of Pathology,

Faculty of Medicine, Recep

Tayyip Erdoğan University

53100 Rize, Turkey

Phone: +904642130491

E-mail: bedirrecep@gmail.com

(C) Copyright 2013 by Turkish

Association of Urology

Available online at

www.turkishjournalofurology.com

\begin{abstract}
Inflammatory pseudotumors (IPTs) are rare benign tumor-like lesions in the epididymis. They result from myofibrohistiocytic proliferation of the parenchymal organs of the body, such as the lungs and genitourinary system. A 48-year-old male patient presented with a palpable left scrotal mass and developed painless swelling within two months. Scrotal ultrasound revealed a $3 \mathrm{~cm}$ solid mass and spermatocele sac in the epididymis. Local excision was performed. Histopathologic and immunohistochemical examination revealed an inflammatory pseudotumor. Only ten cases have been reported in the literature to date. We present our case of pseudotumor of the epididymis as the eleventh case reported in the literature with a brief review.
\end{abstract}

Key words: Epididymis; inflammatory pseudotumor; spermatocele.

\section{Introduction}

Inflammatory pseudotumor (IPM) is a benign tumor-like lesion seen in various organs of our body most frequently encountered in the lungs. Macroscopically it is a non-capsulated lesion with well-defined contours, nodular, and diffuse growth patterns. Microscopically, spindle cell proliferation in loose collagenized stroma intermingled with infiltration of mixed type inflammatory cell. Previously various nomenculatures have been proposed for this lesion including fibroma, pseudofibromatous periorchitis, reactive periorchitis, inflammatory myofibroblastic tumor, atypical myofibroblastic tumor, plasma cell granuloma, pseudosarcomatous myofibroblastic proliferation, pseudosarcoma, and fibrous pseudotumor. ${ }^{[1,2]}$ Paratesticular IPT constitutes $6 \%$ of paratesticular lesions, and tumors. Epididymal IPT is a rarely seen lesion, up to now only 10 cases have been cited in the literature..$^{[2-4]}$

Herein we aimed to discuss clinical, and histopathological features of a rare case of epididymal IPT seen in a 48-year-old patient in the light of the literature.

\section{Case presentation}

A 48-year-old male patient consulted to outpatient urology clinic with left scrotal painless swelling. It was learnt that this swelling was present for 2 months, and grew in size with time. Dysuria, urinary tract infection, and hematuria were not observed. History of trauma, and radiotherapy were not revealed. On physical examination a solid left scrotal mass measuring nearly $3 \times 2 \times 1.5 \mathrm{~cm}$ was detected. On scrotal ultrasonogram, a solid mass at the tip of the left epididymis in the paratesticular region was observed. Besides, a pale yellow colored fluid draining from a spermatocele sac with a diameter of $10 \mathrm{~cm}$ was noted. Organpreserving surgery was applied, and only mass lesion, and spermatocele sac were excised. A solid mass lesion with a diameter of $3 \mathrm{~cm}$, and smooth contours having a grayish-white cross-sectional area was observed. On microscopic examination, chronic inflammatory cell infiltration rich in plasma cells within a collagenous stroma with decussated spindle cells, and proliferation of vascular structures were observed (Figure 1). Immunohsitochemical examination revealed vimentine positivity in collagen bundles, and smooth muscle actin (SMA) positivity within myofibroblastic cells. 


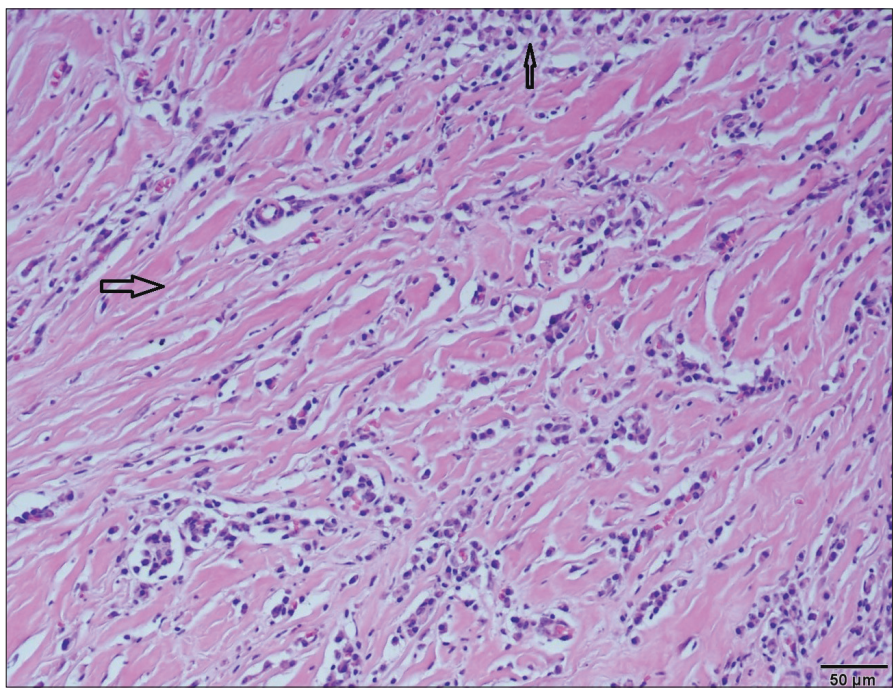

Figure 1. Spindle-like myofibroblastic cells (large arrow), chronic inflammatory cell infiltration (thin arrow), and vascular proliferation in loose collagenous stroma (H\&E x 200)

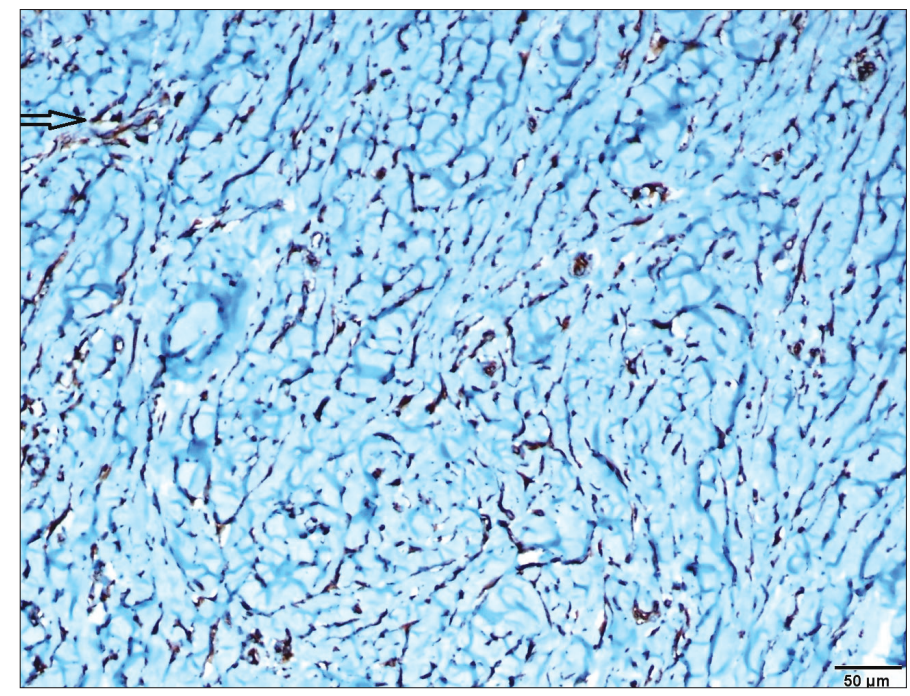

Figure 2. SMA positive areas (arrow) in myofibroblastic spindle cells (x 200)

(Figures 2, 3). Signs of mitosis, necrosis, and anaplasia were not observed. As a result of all these findings, the diagnosis of inflammatory pseudomotor was made. On spermatocele sac, a cystic structure with a fibrous thin membrane lined with a single row of depressed cubic epithelium was observed (Figure 4). Written informed consent form was obtained from the patient.

\section{Discussion}

Epididymal IPT was firstly defined by Lam et al.[5] Mostly, they are detected incidentally without history of any previous

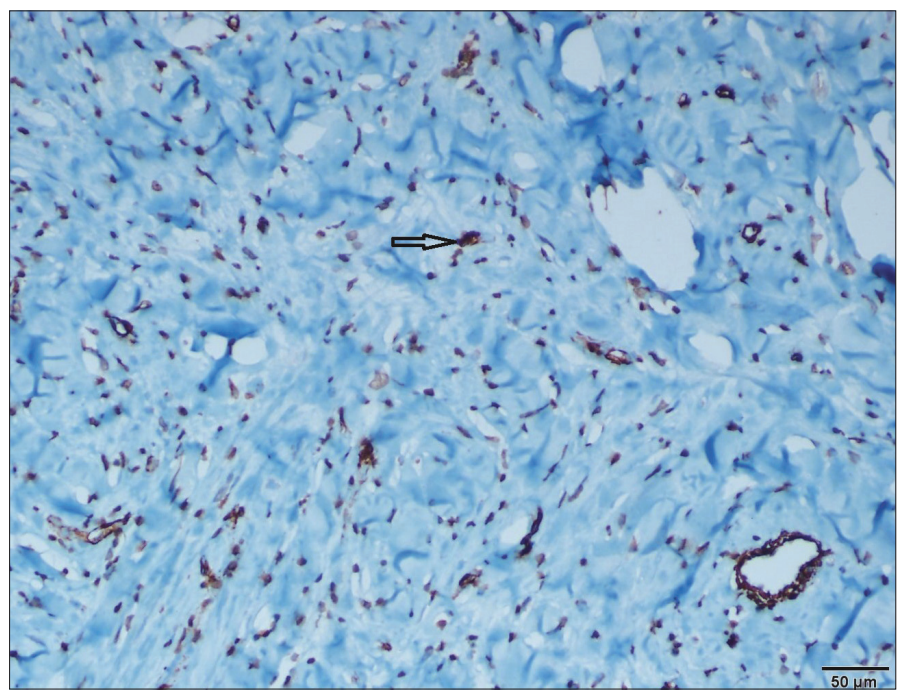

Figure 3. Vimentine positive areas (arrow) between intermingled collagen fibrils

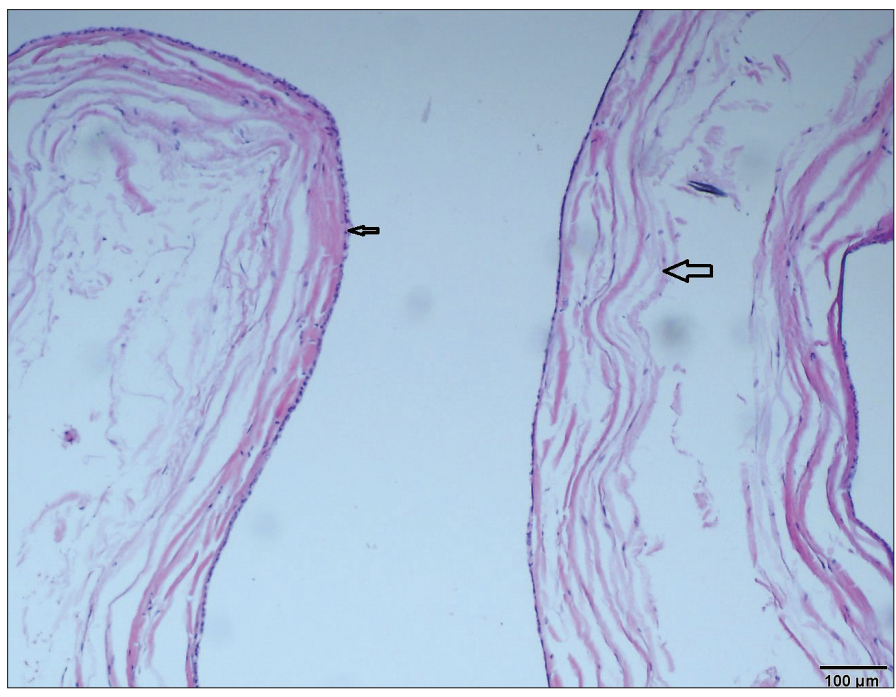

Figure 4. Spermatocel sac with a thin fibrous wall (large arrow) lined with single layer of depressed cubic epithelium (thin arrow) (H\&E x 200)

disease. Although, its etiology is not known fully, it is thought to arise from a reactive response emerging as a result of chronic irritation, infection, trauma, and ischemia. Although EbsteinBarr virus, Mycobacterium avium-intracellulare, and Human Herpes virus- 8 have been suggested to play a role in the etiology of IPT, this association has not been hitherto definitively confirmed. ${ }^{[2,6,7]}$ Chan et al.$^{[8]}$ tested small nuclear RNA 1, and 2 of EBV in reported cases of IPT in lymph nodes, liver, and spleen using in-situ hybridization method. However they couldn't observe EBV RNA in 2 cases with epididymal IPT which might suggest a different etiology stemming from reticuloendothelial system organs. 
Cases with inflammatory psudotumor usually manifest themselves as a scrotal mass. On scrotal ultrasonograms, the nature of the mass lesion, and its relationship with surrounding structures are analyzed. Scrotal ultrasonographic image of paratesticular IPT has been firstly described by Kapur et al..$^{[9]}$ as a lobular hypervascular mass with heterogenous echogenicity. Later on, Megremis et al. ${ }^{[10]}$ defined scrotal ultrasonographic image of a second case of paratesticular mass as a septated, cystic-solid hypoechoic mass impinging on surrounding testicular tissue. Macroscopically, they are mostly solid, nodular lesions with well-defined contours, and a grayish white cross-sectional area occasionally demonstrating cystic, and hemorrhagic areas. Microscopic examination reveals spindle cell proliferation which can demonstrate myofibroblastic differentiation in loose collagenous tissue, mixed inflammatory cell infiltration, and hypervascularity just as seen in granulation tissue.Inflammatory cells rich in plasmocytes which may be associated with lymphocytes, neutrophil leukocytes, eosinophil leukocytes, and histiocytes are observed. Occasionally, hyalinization, and calcification can be detected in the tumor. ${ }^{[2,67,11]}$ Though IPT is a benign tumor, it can often clinically mimick intrascrotal malignancies. For this reason, definitive preoperative diagnosis can not be made. Definitive diagnosis is based on histopathological analy- sis.$^{[12]}$ Immunohistochemical analysis aids in confirmation of the diagnosis. Vimentine, SMA, and CD68 positivity are observed. Besides anaplastic lymphoma kinase (ALK) contained in myofibroblastic cells retains cytoplasmic dyes. It has been reported that in $50 \%$ of the cases, ALK retained cytoplasmic dyes, and especially in young patients it was more strongly expressed. ${ }^{[2,7]}$ Still in our case, vimentine in mesenchymal cells, SMA in smooth muscle cells, and CD68 in histiocytes were positively stained, on the contrary ALK positivity could not be detected. Our findings demonstrate similarities with histochemical, and immunohistochemical findings of some other reported cases in the literature (Table 1).

In the differential diagnosis of paratesticular IPT, various neoplastic, and inflammatory lesions of the testis, and epididymis should be considered. These lesions include myxoid liposarcoma, rhabdomyosarcoma, sarcomatoid carcinoma, inflammatory fibrosarcoma, and liposarcoma, malignant fibrous histiocytoma, spermatocele, varicocele, and rarely tuberculous involvement. ${ }^{[2]}$ In our case mitosis, pleomorphism, and necrosis were not observed. Non-surgical treatment alternatives for IPT outside genitourinary system include drug therapy (cyclosporines, corticosteroids, methotrexate, antibiotics), and radiotherapy. ${ }^{[7]}$

\section{Table 1. A brief summary of the information on cases with IPT as reported in the literature}

\begin{tabular}{|c|c|c|c|c|c|}
\hline References & $\begin{array}{l}\text { Age } \\
\text { (years) }\end{array}$ & Immuinohistochemical findings & Treatment & Location & Follow-up \\
\hline Orosz et al..$^{[1]}$ & 63 & $\begin{array}{l}\text { SMA (+), vimentin (+), desmin (-), } \\
\text { S-100(-), SMA (+), vimentin (+), } \\
\text { desmin (-), S-100 (-) }\end{array}$ & $\begin{array}{l}\text { Radical } \\
\text { orchidectomy }\end{array}$ & Left scrotal mass & \\
\hline Lam et al. ${ }^{[5]}$ & 43 & $\begin{array}{l}\text { Vimentin }(+), \text { SMA }(+), \text { desmin }(-), \\
\text { cytokeratin }(-)\end{array}$ & $\begin{array}{l}\text { Initial antibiotherapy, } \\
\text { then limited surgical } \\
\text { excision }\end{array}$ & Left scrotal mass & $\begin{array}{l}\text { Lack of recurrence } \\
\text { after } 6 \text { months of } \\
\text { follow-up }\end{array}$ \\
\hline Chan et al. ${ }^{[8]}$ & 43 & Polyclonal plasma cells (+) for light chain & Radical orchidectomy & Left scrotal mass & \\
\hline Jha et al. ${ }^{[12]}$ & 32 & Vimentin (+), SMA (+) & Left orchidectomy & Left scrotal mass & \\
\hline Brauers et al. ${ }^{[13]}$ & 73 & $\begin{array}{l}\text { Vimentin (+), CD68 (+), SMA (+), } \\
\text { desmin (-), myoglobin (-), myosin (-) }\end{array}$ & Epididymectomy & Left scrotal mass & \\
\hline Megremis et al..$^{[10]}$ & 45 & $\begin{array}{l}\operatorname{SMA}(+), \operatorname{desmin}(+), \\
\text { CD34 (-) S-100 (-), } \\
\text { cytokeratin }(-), \text { ALK (-) }\end{array}$ & Radical orchidectomy & Left scrotal mass & $\begin{array}{l}\text { Lack of recurrence } \\
\text { after } 3 \text { months of } \\
\text { follow-up }\end{array}$ \\
\hline Dangle et al..$^{[7]}$ & 22 & $\begin{array}{l}\text { Vimentin (+), SMA (+), CD3 (+), } \\
\text { CD20 (+), CD68 (+), ALK-1 (-), } \\
\text { CD138 (-) }\end{array}$ & Radical orchidectomy & Left scrotal mass & $\begin{array}{l}\text { Lack of recurrence } \\
\text { after } 4 \text { years of } \\
\text { follow-up }\end{array}$ \\
\hline Tunuguntla et al..$^{[2]}$ & 17 & & Radical orchidectomy & Left scrotal mass & \\
\hline Our case & 42 & $\begin{array}{l}\text { Vimentin (+), SMA (+), } \\
\text { CD68 (+), ALK (-) }\end{array}$ & Local excision & Left scrotal mass & $\begin{array}{l}\text { Lack of recurrence } \\
\text { after a year of } \\
\text { follow-up }\end{array}$ \\
\hline
\end{tabular}


Treatment of IPT is surgery with many alternatives. Cooperman et al. ${ }^{[3]}$ recommended local excision for extratesticular mass lesions whose discrimination from normal testicular tissue was confirmed by ultrasonographic examination, and its malignancy was excluded by frozen section biopsy. Brauers et al. ${ }^{[13]}$ suggested excision of normal testis, and epididymectomy for a clinically palpable mass measuring $1 \mathrm{~cm}$ in diameter. However Lam et al. ${ }^{[5]}$ recommended orchidectomy for solid scrotal mass lesions which can not be clinically discriminated from testis. Following complete surgical excision of the tumor or combined organ-preserving surgery recurrences are rarely seen. ${ }^{[10]}$ Kapur et al. ${ }^{[9]}$ reported that in recurrent cases where surgical treatment failed, radiotherapy, methotrexate, and corticosteroids could be used. In our case since suggestively benign mass was in extratesticular location, and ultrasonograms could discriminate it from the normal testicular tissue, spermatocele was locally excised together with its sac. Abdominal, and retroperitoneal variants of this tumor have a more agressive potential, however for epididymal IPT any incident of recurrence has not been reported up to now. ${ }^{[7]}$ During one year of follow-up period any incident of recurrence was not detected.

In conclusion, since mass lesions localized in testis, and epididymis can not be clinically discriminated easily as benign, and malignant, for definitive diagnosis histopathological examination should be performed following surgical excision. In the differential diagnosis of paratesticular mass lesions, even though rarely seen, IPT should be kept in mind.

Informed Consent: Written informed consent was obtained from patient who participated in this case.

Peer-review: Externally peer-reviewed.

Author Contributions: Concept - R.B.; Design - R.B., İ.Ş.; Supervision - R.B., C.Y.; Funding - R.B.; Data Collection and/or Processing - R.B., C.Y.; Analysis and/or Interpretation - R.B.; Literature Review - R.B.; Writer - R.B.; Critical Review - R.B.
Conflict of Interest: No conflict of interest was declared by the authors.

Financial Disclosure: The authors declared that this study has received no financial support.

\section{References}

1. Orosz Z, Besznyák I. Diffuse Inflammatory Pseudotumor of the Testis, the Epididymis and the Spermatic Cord. Pathol Oncol Res 1995; 1:75-9.

2. Tunuguntla H, Mishra A, Jorda M, Gosalbez R. Inflammatory myofibroblastic tumor of the epididymis: case report and review of the literature. Urology 2011;78:183-5.

3. Cooperman R, White B, Zincke JP, Kardon D, Andrawis R. Extratesticular inflammatory myofibroblastic tumor. J Urol 2003;169:1473.

4. Gleason BC, Hornick JL. Inflammatory myofibroblastic tumor: where are we now? J Clin Pathol 2008;61:428-37.

5. Lam KY, Chan KW, Ho MHM. Inflammatory pseudotumor of the epididymis. Br J Urol 1995;75:255-7.

6. Karahan N, Çandır Ö. Inflammatory epididymal pseudotumor. A case report. Genel Tip Derg 2006;16:125-8.

7. Dangle PP, Wang WP, Pohar KS. Inflammatory myofibroblastic tumor of epididymis: a case report and review of literature. World J Surg Oncol 2008;6:119.

8. Chan KW, Chan KL, Lam KY. Inflammatory pseudotumor of epididymis and Ebstein-Barr virüs: a study of two cases. Pathology 1997;29:100-1.

9. Kapur P, Treat T, Chuang AT, Hoang M. Pathologic quiz case: paratesticular mass in young man. Inflammatory myofibroblastic tumor of the paratestis. Arc Pathol Lab Med 2004;128:589-90.

10. Megremis S, Papamitsaki E, leromonachou P,Zois E. Inflammatory myofibroblastic tumor of the paratestis sonographic appearance with pathologic correlation. J Ultrasound Med 2007;26:1227-30.

11. Oliva E. Young RH. Paratesticular tumor-like lesions. Semin Diagn Pathol 2000;17:340-58.

12. Jha A, Baidya JL, Batajoo R. Paratesticular fibrous pseudotumor arising from tunica vaginalis. Nepal Med Coll J 2009;11:145-6.

13. Brauers A, Striepecke E, Mersdof A, Sohn M, Fiuzesi L. Inflammatory pseudotumor of the epididymis. Eur Urol 1997;32:253-5. 